\title{
Assessing Students' Feedback in the Teaching of Economics: Dealing with Information Asymmetry in Learning
}

\author{
Mr Calvin Mudzingiri \\ University of the Free State-Qwaqwa Campus, Bag X13, Phuthaditjhaba, 9866, RSA \\ Email:mudzingiric@qwa.ufs.ac.za
}

\section{Doi:10.5901/mjss.2014.v5n23p1181}

\begin{abstract}
Lecturers can assist students much better if they can understand their challenges and opportunities. This study investigates the challenges and opportunities faced by students in an economics class. An understanding of the challenges and opportunities which characterise information asymmetry formed the basis of intervention. The first test was administered after teaching concepts without tracking feedback. The second test was administered after an intervention mechanism was implemented based on feedback from students, elicited using a purposive questionnaire. A Probit Model analysis on the questionnaire reveals that students who passed test 1 belonged to some group discussion, were free to ask questions and spend more time studying economics. A transition matrix analysis after taking cognisance of feedback shows an improvement in performance by students in Test 2, suggesting that lecturers can better assist students if they understand their opportunities and challenges. Active student engagement can go a long way in ensuring that performance in a learning environment is improved.
\end{abstract}

Keywords: Feedback, group discussion, information asymmetry, private information

\section{Introduction}

The high failure rate in economics at Universities is a cause for concern in South Africa and specifically for students in the University of Free State Qwaqwa Campus. A number of issues have been suggested to be real reasons behind the poor performance. These range from poor background in economics, lack of motivation, and poor background in mathematics since the course has strong links to mathematics. Students have exhibited poor performance in answering questions, interpreting graphs, and linking economics theory to practical situations (Bartlett and King, 1990). The general performance in the intermediate economics module at University of Free State Qwaqwa Campus has been hovering around $40-60 \%$ prior 2012 according to university records.

University of Free State Qwaqwa campus is situated in the Eastern part of the Free State Province, in South Africa. It predominantly enrolls black African students mainly from Kwa-Zulu-Natal, Free State province and the rest of South Africa. Although there are no rules that bar the Campus from enrolling foreign nationals and other racial groups, the composition at the Campus is mainly local Black South African students with a small number of foreign nationals and other racial groups. Majority of the learners are from disadvantaged families who at times struggle to raise funds for their education and are highly dependent on Government grants.

The social, economic and demographic issues were not taken into perspective in the study. However, it is critical to note that these hygienic factors may play a pivotal role in learning. Students from poor economic and social background often face challenges in meeting academic demands. At university of the Free State, any student who meets the academic requirements can enroll to pursue Economics. This suggests the students that enroll for economics should be generally capable to do tasks covered in the course.

Students who enroll for economics courses are drawn mainly from Faculties of Economic and Management Sciences, Education and Humanities. A worrying fact is the rising number of students who opt to do Economics while they have a very poor background in mathematics. In addition, South Africa as well as the University of the Free State in particular has seen a rise in more and more students studying Mathematical Literacy other than pure mathematics in high schools. The majority of students who enroll for economics at Qwaqwa Campus would have studied mathematical literacy which leaves them ill prepared for the course. Although this could be one of the contributing factors to poor performance, some students perform well aside from the fact that they have a poor background in mathematics, which could necessarily a case of working hard.

The poor performance cannot continue unmonitored, rather possible solutions need to be investigated. Bartlett and King (1990) points out that there is a general lack of understanding among lecturers of economics about how students 
learn economics concepts. Hence, there is reason to get feedback from the students as a way to improve learning of economics concepts. Information on how other students perform well in the subject while others do badly need to be investigated. The black box with information asymmetry needs to be explored in order for lecturers to design intervention mechanisms. Varied study methods need to be employed as a way to improve teaching and learning of economics.

The aim of this article is to report on a study which investigated assessing feedback from students in the learning of an intermediate micro economics module. The choice of an intermediate course in economics is generally driven by the need to investigate subjects that have a fairly similar background on the content to be taught. Since it is a prerequisite to pass introduction to economics module for one to enrol for intermediate economics module, the assumption will be that students enrolled for the intermediate economics module have general knowledge of the subject. The choice of the intermediate course is driven by the understanding that if students passed the introductory module of economics they would have satisfied the condition of a strong mathematical back ground which is a prerequisite for them to do economics. Taking cognizance of the situation in universities, it is necessary to investigate student feedback and design learning interventions. The study concluded that feedback from students can play a pivotal role in improving learning and performance, more especially student engagement. There is general perception that student engagement can go a long way in improving teaching and learning of economics (Becker and Watts, 200, p. 147).

The following Section addresses literature related to implementation of feedback, different approaches to teaching economics. This is followed by a discussion on the methodology used to assess feedback, challenges associated with assessing feedback, findings, interventions, recommendations and conclusion.

\section{Literature Review}

\subsection{The Process of Assessing Feedback}

Feedback is a two way process in learning and according to Day (1998), it involves students' attendance patterns, how well prepared they are, their willingness to get involved in the class and to contribute to the tasks at hand. Feedback in a learning environment involves questionnaire, assignments, non-verbal, word of mouth, and discussions. In the reciprocal interaction the lecturer should be able to at least identify students' strengths and weaknesses. Feedback can therefore help the lecturer to identify approaches that work for some students so that they may be replicated to other students. This is not an easy task since university classes are usually very large, which makes it very difficult to pick on students who could be struggling with specific concepts.

To circumvent this challenge students are usually broken into tutorial groups. Hounsell et al (1997) concluded that as a feedback technique, group discussion has distinctive strengths: it gives opportunities for exploring issues in depth, weighing the significance of points raised and clarifying students' suggestions. If it is to work well, however, it needs a clear framework or structure which will both help to ensure that key issues are addressed and encourage everyone to make contributions. Students can also form informal class discussion that can go a long way in addressing their misconceptions on the content covered in lectures.

Follow up tutorial questions and class discussions assist students in understanding concepts they have difficulties. There is always a limit to tutorial discussion since university schedule is sometimes rigid such that there is not enough contact time. In some cases, lecturers encourage students to form informal discussions that are usually poorly structured and can only be effective if some of the learners understand the content to be discussed. According to Thelen (1959) group discussion is a powerful technique if students are revising the content covered in lectures and also when preparing for examinations and tests.

University courses are evaluated on periodical intervals, often through the use of student questionnaires, and a good starting point is to find out what information about classes the course monitoring will produce, with a view to supplementing rather than duplicating it. Since the main purpose of this kind of feedback is to gain an overall impression of the effectiveness of a course and suggesting improvement in delivering of content, it will probably not throw much light on particular lecturers or classes, but it will always provide a framework within which to evaluate perceptions of each lecturer's practice as well as student perceptions. Also helpful to lecturers are the informal impressions that accumulate during the process of running sessions that range from verbal to non-verbal.

Keane and Labhrainn (2005) hinted that in order to minimise the effects of those variables known to impact upon students' evaluations, care should be taken to ensure that students remain anonymous. The purpose of the evaluation should also be clearly explained to students and information should be provided regarding the plans for relaying information to students following the analysis of their feedback. Administering a questionnaire should not be witch hunting. Rather, it should be a way of looking for relevant information that will be critical in improving future lectures. A 
free environment helps students to give a critical evaluation on the ground and instils confidence in students.

During the course of a lecture, feedback is usually a routine of activities that can help the lecturer to evaluate the level of understanding of students. The lecturer can use lead questions as well as general question and answer session to tap the information gaps. One of the common feedbacks during the course of lectures is the non-verbal feedback. A lecturer should be able to tell whether generally the students are following the concepts under explanation. If for example, an explanation is made and from a non-verbal expression students show that they are not following the concept, there will be need to revisit the subject. Learning should be anchored on providing a solid background of ideas reciprocated with a clear two way feedback.

A summative way of getting feedback from the students is by way of test, assignment and examination (Keane and Labhrainn, 2005, p. 7). During the course of the semester students reflect their understanding of concepts learnt through performance in written tests, assignments and examination. Although performance in the final examination may not necessarily be revised, assignment during the course of the semester may exhibit students' weaknesses which my require scaffolding. The lecturer may have to revisit such concepts or suggest questions that help students understand misconceptions. Performance in final examination helps the lecturer to reflect on ways one can improve future classes with different students.

Feedback on students requires constant evaluation and it is a process not an event. It is a cyclical process that is continually implemented with the aim to improve learning in the classroom. (Hounsell, 2003, p. 210) suggested a cyclical evaluation model that include the process of clarifying context and focus, devising a feedback strategy, gathering feedback, analysing and interpreting the feedback, agreeing on action, implementing changes. This cycle is repeated over and over again in a bid to ensure target goals are accomplished.

In a learning environment there is a dear need for constant evaluation in a bid to maximize learning. Constant reflection on activities will provide an insight on the strength and weakness of strategies that are employed. Strategies that work should be adopted while those strategies that are not producing good results are discarded. The study followed the evaluation cycle procedure and it is critical to note that since the period under study is too short, some of the evidence collected can only be used in future learning environments with different set of students or with similar set of students under different courses.

\subsection{A Perspective into Teaching Economics}

The prime goal of teaching and learning economics is to ensure that students acquire skills that they will apply in daily life. Economics solutions have been quite elusive in most economies, with a great number of countries faced with high unemployment, low growth, unstable economies, and poverty. The big question is, are students able to think like Economists? Bartlett and King (1990) noted that although there is not much that has really been tried to test whether students think like economists, there has been some disappointment with how well the students do on more traditional measures of performance.

This suggests that students should exhibit understanding of concepts covered in economics in a way they will be able to at least relate economic events happening in their environment where possible. In reality the expected outcome has not always been realised, which frustrates the efforts by instructors. The reasons for these disappointments are many and may apply only to particular experiments; however, there is cause to suspect that economic education is less than it could be, for two reasons: There is a general lack of understanding among lecturers of Economics about how students learn and there is a reluctance to teach economics as a science (Holt, 1999).

Evidence on the ground suggests that lecturers should strive to investigate ways that can improve and increase understanding of economics concepts. It may require designing of a curriculum that gives students continuing opportunities for hands-on experience, direction, and support over the course of their studies and not just at the end of or at a few points during their academic careers. Bloom et al (1971) described the general learning process for students as a sequential process. His taxonomy of educational objectives suggests that students begin learning at a very rudimentary level of understanding, such as basic definitions and facts. In an effective learning environment, students then progress to understanding simple functional or causal relationships. This suggests that an interactive way of learning is a powerful tool in improving students learning.

A good example of two step interaction in economics is that students need to know the precise definitions of income and gross national product in order to understand the national income accounts. While practical approach to imparting knowledge to students is not always feasible due to resources constraints in institutions, accessing feedback from learners on materials taught can go a long way in reinforcing information gaps. Above all, information learned is easily forgotten unless it is constantly reinforced. Feedback can play a pivotal role in redesigning study methods to 
improve learning.

A number of researchers have suggested that economics be taught as a laboratory science. Teaching economics as a science means developing laboratory components for courses. Laboratory exercises can take a variety of forms, such as, spending additional class time running computer simulations, doing statistical analysis, discussions and actually performing experiments. The purpose of these exercises is to give students the opportunity to have a personal hands-on experience, as do students in the natural and life sciences (Bartlett and King, 1990, p.182). The big question is; can all crucial economics concepts be covered in these experiments? Will there be enough time to cover all course outcomes?

Holt (1999) hinted that traditionally, economics has not been an experimental science, and this fact has shaped the kinds of questions addressed and arguments presented. Keynes (1936) stressed the important role of conversation and criticism in evaluating economic arguments, "....where it is often impossible to bring one's ideas to a conclusive test either formal or experimental." As a result, theories often rose or fell in popularity on the basis of generality, mathematical elegance, or clever terminology. Samuelson (1947) noted that economics lacked the "self-cleansing" nature of a hard science and therefore, he stressed the methodology of deriving comparative statistics in predictions of changes of observable variables. In a nutshell, not all economics concepts can be experimented on. This limits student engagement with practical economic situations that may help them to understand concepts clearly.

In addition, many instructors are hesitant to run a classroom experiment for fear of losing control or of obtaining anomalous results that will be difficult to explain. Classroom experiments are more difficult to use effectively in large classes typical of universities, since it is the personal involvement that stimulates student interest. Similarly, the Socratic method of extracting lessons from these exercises is more effective in smaller classes. It is very hard for the typical lecturer to restrain the impulse to ask a question, and if nobody answers it, to go straight to the final answer (Holt, 1999, p.5). It may be more effective to think about follow-up questions, to take incorrect answers seriously and let students critique them.

Another reservation about classroom experiments is the time involved. Discussions and experiments may require most or all of a typical class period to cover a particular concept. Only important concepts merit this amount of time if other teaching methods are exploited. This is somewhat a matter of teaching philosophy, that is, whether it is better to survey a lot of material or to reinforce key ideas. In any case, there is not much risk in trying several classroom experiments and evaluating the outcomes before introducing more. However, strict timetables in universities are not usually suitable for time consuming classroom experiments. The truth of the matter is specific concepts will require particular method of teaching.

Becker and Watts (2001) noted despite these inherent problems, lecturers continue to believe that the variety of teaching methods available for use in undergraduate economics courses offer the means for any instructor to increase both student learning and interest in the subject. Given some preparation and a modicum of sensitivity to student responses, lecturers may expect their students' ratings to go up, along with what students learn, when students are actively involved in the classroom learning experience. This entails that any teaching method used can be quite helpful if only students exhibit understanding of concepts through some feedback.

Although chalk and talk method of teaching dominates most lectures and many students prefer teaching that enables them to listen passively, teaching that organizes the subject matter for them and that prepares them well for tests is desirable. Research concluded and confirmed better retention, thinking, and motivational effects when students are more actively involved in talking, writing, and doing (Becker and Watts, 2001, p. 449). If students are able to communicate concepts amongst their peers and in front of class or in a group discussion, they would have an in depth understanding of concepts at hand.

\subsection{Asymmetry information in learning}

To understand the essence of feedback in learning we can view the learning set up in the context of principal and agent, where the principal is the lecturer and the agent is the student. In many circumstances, both parties have private information about the agent's suitability to the task. The agent usually has better knowledge of his previous performances and of the relevant circumstances (his effort intensity, the distinctive factors that may come into play). The student often also receive private signals about the attractiveness or unpleasantness of the task, either from third parties, or from having performed similar ones in the past, as well as simply from own experience when carrying out the current task (Benabou and Tirole, 2003, p.496).

The lecturer, on the other hand, often has complementary private information about the task or the student's prospects from it. For example, a lecturer is better able to judge the difficulty of the subject or assignment, together with the student's ability, and conditions of the probability of success. The principal may know better than the agent whether 
the task is attractive, in terms of either being enjoyable to perform, or having a high payoff for the agent. The theory of principal and the agent suggests that inability to have enough information results in a sub-optimal outcome. Although the theory is more relevant at work place and in political set up, it can also be mimicked in a learning environment where information may be imperfect

In the set up the lecturer can provide critical guidance to the students if he/she understands their weaknesses and strengths. The principal should have an idea of what works better for the students and the approaches that decisively improve learning. If the lecturer is armed with the private information privy to the students, appropriate interventions may be crafted targeting specifically the goal to improve understanding of economics concepts. On the other hand, students should have an idea of the tasks and concepts that they are supposed to accomplish. For example students know pretty well that for them to attain the qualification they should pass the required modules. It should be noted that assistance mainly critical to those students who will be struggling with the content. A better option will be to investigate those teaching methods that help other students perform well and take the stage as the initiating point in scaffolding the rest.

The idealism concept stresses the need for students' experiences to be put in perspective. Students should have a firm background of concepts under consideration for them to be able to provide solutions to particular tasks. Students cannot be expected to be able to solve problems if they do not have an idea of the difficulty at hand. This boils to the fact that students need to be exposed to knowledge before they can tackle problems. However, the biggest challenge within mix is some students understand concepts much faster than other students. The effort that students put in their studies varies from one individual to another and can form a critical basis for overall performance.

In a learning set up, the lecturer should provide enough information that enables the students to tackle privately prepared tasks, that is, examinations and tests. The lecturer does not divulge examinations and tests before they are written. Whether a student asks a question that is not in an examination, the lecturer will explain the concept as if it is in the examination. The lecturer does not differentiate explanations on concepts whether they are going to be tested or not. The aim of this behaviour is to encourage students to understand a wide range of concepts that help them to think like economists.

The use of questionnaire, tests, and discussions to mine out feedback from students is way of gathering hidden information on students' knowledge. It is a way of gathering students' private information on how they learn and how well they understood concepts taught. The prime goal is to investigate whether one can successfully use feedback from students in improving teaching and learning of economics.

\section{Methodology}

In the first place, students were taught using conventional methods and they then wrote their first test. A survey in the form of a structured questionnaire was administered to investigate what influenced students' performance in test 1. A purposive sampling technique was used to find information from students enrolled for an intermediate micro economics course. The principal-agent concept (Benabou and Tirole 2003) forms the basis of the use of a questionnaire. The lecturer is the principal who would like to find private information of the agent who happens to be the student. The reasoning behind is that students should be fully aware of studying methods that help them perform well or badly. More so, information asymmetry in the learning environment prevents optimization of learning. The students know pretty well those concepts they struggle with as well as what they are comfortable with. They also know what works better for them. Precisely, the questionnaire looked at the study methods and techniques that help students pass test 1.

A probit Econometric model to analyse the questionnaire was used. Where

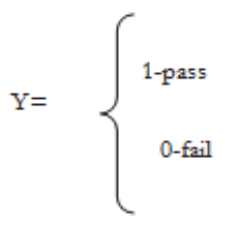

$Y$ is the dependent variable influenced by $X_{1}, X_{2} \ldots, X_{12}$ set of questions

$P i=E(Y=1 \mid X i) \quad$ Where $p_{i}$ is the probability of student passing (Gujarati, 2004, p.598), marginal effects of the model were calculated on the responses provided by the students.

A set of seven questions were given to the students on a particular day after writing Test 1 . Only 50 students out of a possible 78 who were present in the lecture session answered the questionnaire. To ensure that students do not provide biased answers, the dependent variable question that looked at whether the student passed or failed was asked at the end. 
The set of questions that were asked focused on student performance in Test 1, lecture attendance, free to ask questions, study time set aside, owning reference book, engagement in group discussion, and whether group discussion is helpful. All the questions that were asked had closed answers with spaces provided for students to provide open ended answers. The closed answers provided ranged from (yes/No), and (yes/No/not sure).

Feedback from the questionnaire formed part of improvements in teaching in preparation of test 2 and the final examination. Besides using feedback from the questionnaire other forms of feedback namely; discussions, tests, assignments, non-verbal responses, student consultation as well as question and answer sessions were exploited to improve students' performance in learning economics. Feedback from the agent (students) to the principal (lecturer) is some private information that is useful in improving learning. The lecturer must have private information in order to be able to design some intervention mechanism critical in assisting students understand economics concepts. Feedback is used to help poorly performing students better known as, 'at risk students'.

Three forms of discussions provided data namely; class discussions, tutorial discussions and students' informal discussions. Class discussions were conducted during normal lectures where possible and observations were made. This also includes question and answer sessions which helped explore how much students understood the covered content. Students' consultation provided critical feedback on how much learners comprehend content. The lecturer designed follow up discussions on misconceptions on covered work that was picked from students' consultation. The researcher observed and noted nonverbal responses especially when explaining concepts and students appeared not to understand concepts. Tutorial questions focussing on covered concepts were given to tutors and were discussed by students with the help of tutors. Feedback was provided to the researcher by the tutors. An investigation on informal group discussions as students prepare for tests and examination was also conducted. Salient features picked through the course of learning are documented in the next section.

Follow up on concepts poorly answered in tests and assignments were carried out. Badly performed concepts in assignments were looked at and followed up by way of revision. Counselling was provided to students showing declining performance in their work. In short, the lecturer tapped feedback from various sources in a bid to improve learning and assisting 'at risk students'. The study could not concentrate on one source of feedback because this could set classrooms as laboratories instead of learning environments. Data from test 1 and test 2 were captured as well as analysed using a transition matrix with STATA statistical package.

\subsection{Limitations}

This study was carried in a semester, which could be too short a period to observe a longer term impact of the revision process. Although the findings may be helpful in advancing learning, repeated experiments could give a solid insight on best teaching practices.

\section{Results}

An analysis using probit econometric model suggested that out of the seven questions asked in the questionnaire, only four factors significantly influenced students' performance. Students who passed Test 1 were free to ask questions, belong to some informal discussion group, indicated that group discussion helpful and they did spend more time studying economics (Table below). This suggests some students are familiar with study methods that help them to pass, which in some way may help lecturers to spread the working strategy across the whole group.

Probit analysis of a questionnaire administered after students wrote Test 1

\begin{tabular}{|l|c|}
\hline Variable & Marginal effects \\
\hline Free to ask questions & $0.35^{\star \star}$ \\
\hline Belong to some informal discussion group & $0.84^{\star \star \star}$ \\
\hline Group discussion helpful & $0.40^{\star \star}$ \\
\hline Spend more time studying Economics & $0.47^{\star *}$ \\
\hline Own reference Textbook & -0.13 \\
\hline attendance & -0.11 \\
\hline
\end{tabular}

Students that belonged to some informal group discussion had a high marginal effect of 0.84 which means that there is an 84 per cent chance for a student passing if one participates in a group discussion and is highly significant at 1 per cent 
level of significance. The conclusion is that students are most likely going to perform well if they take part in group discussions. Since group discussions that were used by the students for test 1 were basically informal, this prompted designing of properly structured group discussion by the lecturer. A follow up question on Group discussion revealed that there is a 40 per cent chance of passing on those students that believed group work was helpful for their success in test 1. However, a lower percentage on the success attached to group work effect perception could have been due to underestimation of the benefits attached to group work. Overall, the respondents believed in the use of group discussion as a powerful weapon in learning concepts confirming, Keane and Labhrainn (2005) assertion that student can improve their performance if they work in a group. The results seem to reveal hidden information that helped students learn and understand economics concepts.

The time a student spends studying for the economics course which was captured as a continuous variable significantly improves student performance. A 1 per cent increase in time spent increases the chance of a student passing by 47 per cent and it is significant at 1 per cent level. This clearly shows that hard work pays as hard workers are more likely going produced better results than lazy students. This comes as no surprise as conventional wisdom suggests a huge effort in accomplishing a task is usually associated increasing returns. Students should be encouraged to work hard in order to achieve good academic results. There is a need for constant guidance and counselling as a way of encouraging students to work hard to meet the demands of tests, examinations and handling work related situation.

The courage to ask questions in lectures and consultations significantly influence the performance of the students. Given that a student is free to ask questions during lecture sessions there is a 35 per cent chance of passing a test and it is significant at 5 per cent level. This suggests that for improved performance student should be able to pose questions on concepts they are not clear with. An enabling environment should be created in lectures to ensure that students are motivated seek explanations on the concepts that may not be clear to them. Two variables were found to be insignificant namely owning a reference book and whether the student was able to attend classes. Failing to attend classes reduced the chance of a student passing by 11 while failure to own the reference textbook reduced the chance of someone passing by 13 per cent.

The questionnaire played a crucial role in eliciting hidden information on student performance. The working strategies used by successful students can be replicated to the whole class to improve poorly performing students. Poorly performing students are better known as 'at risk students' at the University of the Free State. Since students indicated learning strategies that generally worked for them and they generally know where they have weaknesses, this became the initiating point.

The findings concluded that at risk students were not free to ask questions. This prompted the lecturer to ask follow up questions, more especially, on questions asked by other students during lectures and consultation times for their benefit of the whole class. Tutorial questions were also prepared specifically meant to address the knowledge gaps exhibited by students during consultation, tests, assignments and lecture times. The researcher instructed the tutors to divide students into tutorial groups during tutorial sessions. Clearly structured group discussion sessions formed for tutorial sessions and students were allowed to solve problem in the groups. The lecturer provided the tutors with memo for questions and poorly performing groups were offered special attention. The increase in targeted work was meant encourage students to spend more time studying to enhance their understanding of the subject. The idea behind all these initiatives was to capture the gaps that exist on the at risk students. Misconception exhibited by one student is likely to be a problem to a number of students in class; hence follow up explanation on questions asked by students who are free to ask questions during consultation hours was done by the lecturer.

The intervention was time consuming and it created extra work for the lecturer, tutors and the students; however a general improvement was realised in test 2. A transition matrix analysis (Table below) was used to investigate whether there was an improvement in performance. It was concluded that 40 per cent of students that got a mark between 0- 40 per cent in test 1, failed test 2 and 60 per cent of the students that scored a mark between 0-40 per cent in test 1 passed test 2 with at least 50 per cent. Only 33 per cent of the students who had a mark between 41-50 per cent in test 1 failed test 2 and the rest scored a mark above 50 per cent. The analysis also shows that of the students who scored a mark between 51-60 per cent, 61-70 per cent, 71-74 per cent and 75-100 in test 1, the percentages of students who failed test 2 are 10, 7, 7 and 0 respectively. This shows a reduced failure rate and a general improvement in performance in test 2 that could be attributed to the interventions employed. 
Transition Matrix analysis, $\mathrm{N}=80$

\begin{tabular}{|c|c|c|c|c|c|c|c|c|}
\hline & \multicolumn{7}{|c|}{ TEST 2 } & Total \\
\hline \multirow{4}{*}{ TEST 1 } & & $0-40$ & $41-50$ & $51-60$ & $61-70$ & $71-74$ & $75-100$ & \\
\cline { 2 - 8 } & $0-40$ & $40 \%$ & $0 \%$ & $10 \%$ & $20 \%$ & $20 \%$ & $10 \%$ & $12 \%$ \\
\cline { 2 - 8 } & $41-50$ & $0 \%$ & $33 \%$ & $16 \%$ & $17 \%$ & $17 \%$ & $17 \%$ & $8 \%$ \\
\cline { 2 - 8 } & $51-60$ & $5 \%$ & $5 \%$ & $23 \%$ & $11 \%$ & $28 \%$ & 28 & $23 \%$ \\
\cline { 2 - 8 } & $61-70$ & $3 \%$ & $4 \%$ & $10 \%$ & $13 \%$ & $33 \%$ & $40 \%$ & $37 \%$ \\
\cline { 2 - 8 } & $71-74$ & $7 \%$ & $0 \%$ & $20 \%$ & $33 \%$ & $20 \%$ & $20 \%$ & $19 \%$ \\
\cline { 2 - 8 } & $75-100$ & $0 \%$ & $0 \%$ & $100 \%$ & $0 \%$ & $0 \%$ & $0 \%$ & $1 \%$ \\
\hline Total & & $8 \%$ & $5 \%$ & $17 \%$ & $17 \%$ & $24 \%$ & $29 \%$ & $100 \%$ \\
\hline
\end{tabular}

Furthermore, all in all 20 per cent of the students failed test 1 compared to 13 per cent that failed test 2 . There has been a 7 per cent improvement in the pass rate in test 2 compare to test 1. Comparing upper end of the marks scored in the two test also suggest that the interventions did bear fruit. A total of 24 per cent of the students scored a mark between 71-74 per cent in test 2, compare to 19 per cent of the students scoring the mark in the same range in test 1 . Only 1 per cent of the students scored a mark above 75 per cent in test 1 compared to 29 per cent of the students getting a mark in the same range in test 2 . It is evident that generally the quality of the performance improved quite significantly.

Observations were made on students who prepared for examination through group discussion and found out that they generally performed better than students who prefer to study as individuals. In a particular group of students that revised together and prepared for final examination, all the members passed with the highest scored mark of $79 \%$ and the least scored mark of 59\%, a confirmation of Day (1998) who asserted that group discussion is an essential studying method, which can improve learning.

About $80 \%$ of the students counselled showed an improved performance in their work. Students who received counselling are the ones who had either performed better in one test or performed badly in another. The counselling process was not usually formal but it was random. Students opened up on some of their problems and sometimes they would attend formal counselling session with the lecturer. Counselling is a powerful tool in learning and can ensure improved performance to students that have potential

There has been a general improvement in classroom participation. However, the percentage of students who actively participate in lectures is still low. The improvement in performance can be attributed to assessment of feedback and suggesting appropriate intervention during the learning process. The trends observed shows that majority of students who participate in lectures also perform well in assignments, test and examination.

Learning environment in any university faces challenges. University of the Free State, Qwaqwa Campus is not an exception. Major factor observed that contribute to students' poor performance is inconsistence in lecture attendance. Students usually attend half lectures as they indicate that they have clashes. There is generally low attendance especially when students are writing tests and assignments in other courses. This suggests that the response on class attendance was overestimated or students could have given a misleading response. Students usually study to pass rather than understanding concepts. They usually intensify studying over a short period.

More so, fewer students are willing to participate in groups. In most cases students struggle to express themselves in the medium of instruction in this case English. Further, if they are left to discuss on their own, they prefer using their vernacular languages. This creates misconceptions since there are sometimes no precisely equivalent terms in the vernacular language that relates to economic terms. These shortcomings render the use of student participative learning difficult. If students could freely participate in learning, it will make it easy to identify their weaknesses.

\section{Conclusion}

Students have their own private information; they know concepts that are familiar or unfamiliar to them. If lecturers were able to find out students' private information on learning, this would go a long way in improving learning and they could effectively deal with student learning challenges. Having perfect information on students' strengths and weakness assists lecturers in designing appropriate learning intervention. Assessing students' feedback is an effective way of bridging information asymmetry in learning. Although in universities there is limited contact time, students must be encouraged to form and participate in group discussions when solving problems. Above all, students should be prepared to study more hours if they have difficulty in understanding economics concepts. A conducive environment for students to be able to freely ask questions should be created in learning set ups. Student feedback is a critical tool to investigate how much learners understand and can assist in pin-pointing knowledge gaps and suggesting intervention mechanisms. 
Perhaps areas that require further exploration are best techniques that can assist lecturers in collecting as much students' feedback as possible. This could go a long way in alleviating learning challenges among students. It can also be vital to apply the concept in other different set ups as a way to investigate whether improvements can accrue due to the constructive use of feedback.

\section{References}

Bartlett, R. L., and P. G. King (1990). "Teaching Economics as a Laboratory Science." Journal of Economic Education: 181-193.

Becker, W. E (2000). "Teaching Economics in the 21st Century." The Journal of Economic Perspectives 14 (1): 109-119.

Becker, W. E., and Watts, M (2001). "Teaching Economics at the Start of the 21st Century: Still Chalk-and-talk." The American Economic Review 91, no. 2 pp. 446-451.

Becker, W. E., and Watts, M (1995). "Teaching Tools: Teaching Methods in Undergraduate Economics." Economic Inquiry 33 (4): 692700.

Benabou, R., and J. Tirole (2003)."Intrinsic and Extrinsic Motivation." The Review of Economic Studies 70 (3): 489-520. http://restud.oxfordjournals.org/content/70/3/489.short.

Bloom, B.S., Hastings J.T, and Madaus, G.F(1971). Handbook on formative and summative evaluation of student learning. New York: McGraw-Hill.

Coffey, M., and Gibbs, G (2001). "The Evaluation of the Student Evaluation of Educational Quality Questionnaire (SEEQ) in UK Higher Education." Assessment \& Evaluation in Higher Education 26 (1): 89-93, 2001. http://www.tandfonline.com/doi/abs/10.1080/02602930020022318.

Day, K, Grant, R and Hounsell, D (1988). Reviewing your Teaching, Edinburgh and Sheffield: University of Edinburgh, TLA Centre.

Day, K. Tutoring and Demonstrating: A Handbook (1998). The University of Sheffield. U K.

Gujarati, D. N (2004). Basic Econometrics, Fourth Edition The McGraw-Hill Companies.

Holt, C.A (1999). Teaching economics with classroom experiments: A symposium. Southern Economic Journal pp. 603-610.

Hounsell D, Tait H, and Day K(1997). Feedback on Courses and Programmes of Study, Centre for Teaching, Learning and Assessment, University of Edinburgh

Keane, E., Labhrainn, I (2005). Obtaining student feedback on teaching \& course quality. Briefing paper 2

Keynes, J M (1966). The general theory of employment, interest, and money. New York: Harcourt, Brace \& World, Inc Samuelson, Paul A (1970). Foundations of economic analysis. New York: Atheneum

Thelen, H. A (1959). "Classroom Grouping of Students." The School Review 67, no. 1 pp. 60-78. http://www.jstor.org/stable/10.2307/1083684. 